\title{
Modelling the Effect of Housing Design Unit Contract Packaging on Mass Housing Project Team Communication Performance
}

\author{
*Titus Ebenezer Kwofie, Emmanuel Adinyira and Frank Fugar
}

Published online: 31 July 2016

To cite this article: Titus Ebenezer Kwofie, Emmanuel Adinyira and Frank Fugar. (2016). Modelling the effect of housing design unit contract packaging on mass housing project team communication performance. Journal of Construction in Developing Countries, 21 (1): 35-50. doi: 10.21315/jcdc2016.21.1.3

To link to this article: $\mathrm{http}: / / \mathrm{dx} . \mathrm{doi} . \mathrm{org} / 10.21315 / \mathrm{jcdc} 2016.21 .1 .3$

\begin{abstract}
Studies exploring success on mass housing projects (MHPs) continue to cite communication ineffectiveness inherent from the unique attributes of mass housing as a major problem in the delivery. Unfortunately, these studies fail to establish the nature and extent to which the observed communication ineffectiveness is attributed to the unique characteristics displayed by MHPs. Here, this study aims at exploring the influence of the housing design unit contract packaging (HDP) features of MHPs on project team communication performance. By adopting a questionnaire survey and the use of structural equation model (SEM), the study used empirical data collected from project team leaders on mass housing project sites in Ghana to assess the communication ineffectiveness inherent in the HDP attributes. The evidence gathered from the empirical study indeed supports the hypothesis that the HDP features of MHPs significantly contribute to communication ineffectiveness related to information flow and information composition among the project team. These findings affirm the uniqueness of MHPs and suggest the need for project teams and stakeholders on mass housing to adopt communication methods, medium, strategies and management approaches that fit the mass housing project environment to engender managerial and communication efficiencies in mass housing delivery.
\end{abstract}

Keywords: Communication ineffectiveness, Mass housing projects, Housing design unit contract packaging

\section{INTRODUCTION}

Mass housing projects (MHPs) delivery continues to suffer from many problems and ineffectiveness that are perceived to be inherent from its unique characteristics. Notable among these problems that have engaged the attention of stakeholders and practitioners is the continuous experience of managerial inefficiencies and communication ineffectiveness that are perceived to be inherent from the unique characteristics of MHPs (Enshassi, 1997; Enshassi and Burgess, 1991). Literature give empirical evidence on the recognition of the significant role communication effectiveness plays on project performance and delivery successes and thus encourage more research to be done (Skulmoski and Hartman, 2010; Project Management Institute, 2008). Effective communication across all project phases is perceived as a critical success factor that connects all the other factors of project success as well as team integration (El-Saboni, Aouad and Sabouni, 2009). However, construction projects especially projects of unique attributes and

Department of Building Technology, Kwame Nkrumah University of Science and Technology, Kumasi, GHANA

*Corresponding author: teeagk@yahoo.co.uk

(C) Penerbit Universiti Sains Malaysia, 2016 
characteristics such as MHPs seemingly suffer from lack of effective communication among the project team which are mainly inherent from the unique project characteristics and project environment. Indeed, Adinyira, Ahadzie and Kwofie (2013) established that, MHPs exhibit unique physical, organisational and operational features.

According to Ahadzie, Proverbs and Olomolaiye (2007), MHPs exhibit unique characteristics in its design units as well as its contract packaging that require unique management skills and approach in its delivery. Likewise, Ahadzie, Proverbs and Sarkodie-Poku (2014) established that the repetitive design unit of MHPs, contract packaging and the multiple site nature offer heightened communication and documentation challenges. However, this assertion is yet to be subjected to empirical assessment. Given the significant role communication plays in project success and team performance, it is thus very crucial for more studies to be done to assess how the unique characteristics of MHPs contribute to the overall project team communication performance. This is induced by the fact that understanding of the communication ineffectiveness inherent from the project attributes remains very crucial towards evolving and adopting communication media, strategies and management approaches that suit the unique project environment. This is thus very necessary in engendering the needed communication effectiveness for project success. The main aim of this study is to explore the contribution of the unique housing design unit contract packaging (HDP) features of MHPs on project team communication performance.

\section{CONCEPTUAL MODEL}

The study adopted a conceptual model developed by Kwofie et al. (2014) which was underpined by the attribution theory of communication. The adoption of this model was influenced by the fact that, it was developed based on the practical, theoretical and contextual characteristics and dynamics of construction project delivery in the Ghanaian construction industry (GCl). Additionally, it incorporates the cultural setting of the construction industry in Ghana which is similar to other developing countries in sub-Saharan Africa. The model identified behavioural competencies and project related factors (project features) as the main attribution of MHP team communication outcome. Hence by adopting the model ensures theoretical validity and triangulation of the concepts and dynamics of the industry in Ghana. By focusing on the project related factors, the model typified that the unique features of MHPs are among the main causal locus of the communication performance outcome among mass housing project teams. From the model by Kwofie et al. (2014), five main features were identified. This studies focus on the HDP features. Again, here, six variables define the HDP features and were operationalised and denoted as the exogenous factors. These variables theoretically define the unique HDP attributes of MHPs that are perceived to contribute to the communication performance outcome among the team. The communication performance outcome was measured by 16 variables operationalised as the two main endogenous factors defining information flow and information composition communication performance among the project team in the model. In structural equation model (SEM) analysis, exogenous and endogenous variables are also interpreted as independent and dependent 
variables respectively (Iacobucci, 2010; Kline, 2011). The endogenous factors were developed from the communication performance outcome indicators by the Construction Industry Institute (CII) (1997) which has remained the most extensive and exhaustive factors that has been used in several recent studies of communication performance assessment (see Thomas, Tucker and Kelly, 1998; Murray et al., 2000; Xie et al., 2010; Liu, 2009). Hence for the purposes of triangulation and theoretical validity as well as given that the current study if focused on the quality of the information flow and outcome due to the influence of the unique features of mass housing, this approach is deemed very viable.

The 16 communication performance indicators relate to the accuracy, completeness, understanding, gate keeping, timeliness, barriers and procedures of the communication on the construction project (CII, 1997). Hence, it is theorised that the communication effectiveness outcome on MHPs due to the influence of the unique HDP features can be conceptualised and operationalised: hence from a theoretical perspective, the hypothetical construct generated was that, the HDP features of MHP significantly contribute to the communication ineffectiveness experienced by the project team. A more vivid hypothesised structural model perceived and to be tested with the six identified HDP features of mass housing significantly induce information flow and information composition communication ineffectiveness among the project team on MHPs.

\section{HDP Features of MHPs}

This attribute of mass housing explores the design concept, construction elements and technology adopted in the housing units in the mass housing scheme as well as the contract packaging. HDP here refers to and encapsulates the design characteristics and contract attributes exhibited in the contract packaging for procurement and delivery. MHPs often adopt repetitive designs that may be single or several in the contract packaging. There are wide ranges of housing design types that may be adopted for use in mass housing development either by speculative delivery or user defined depending on their suitability (Ahadzie, Proverbs and Olomolaiye, 2007; Adinyira, Ahadzie and Kwofie, 2013). They are often developed into contract packages that may contain various different types of design typologies or same unit types in each package. As noted by El-Rayes, Ramnathan and Moselhi (2000), housing design types often used in mass housing range from terraced house, semi-detached, town houses, detached houses, courtyard houses, mansion block, decked access block, tower blocks or split-level depending on the needs of the market and thus offer managerial and packaging implications. Here in this study, the unique HDP features of MHPs are defined by six variables (features) that compose the factor (see Appendix). The six variables composing the unique HDP feature factors in the model was denoted as the exogenous variables.

\section{Communication Performance Factors among MHP Teams}

The assessment of the Project Team Communication Effectiveness was undertaken by operationalised 16 variables (see Appendix). This was conceived as the endogenous (Dependent Variable-Factor) in this study. As indicated by Xie (2002) and Xie et al. (2010), by adopting the communication effectiveness indicators by 
the Cll (1997), revealed that induced communication ineffectiveness experienced among the project team on construction projects are perceived in the flow of the information and the composition of the information. Hence, by drawing on the theoretical perspective of this study, the analysis of the communication effectiveness among the MHP team was conceived in two main dimensions as in the flow of the information and the composition of the information. Here the Project Team Communication ineffectiveness associated with the flow of information factor were defined by seven indicator variables whiles that associated with the composition of the information factor was defined by nine variables (see Appendix). The method and analysis of the empirical data to identify the contribution of the HDP features of MHPs to the Project Team Communication Effectiveness is presented in the proceeding section.

\section{STUDY METHODOLOGY}

The study adopted a quantitative design approach which was influenced by similar studies as well as the theoretical requirement of the intended Structural Equation Modelling analytical approach (lacobucci, 2010; Xie et al., 2010; Liu, 2009; Xie, 2002). The variables on the information flow and composition communication ineffectiveness and the unique HDP features (Adinyira, Ahadzie and Kwofie, 2013) were developed into a structured questionnaire which was administered to project team leaders on mass housing construction project sites of active mass housing organisations who were members of Ghana Real Estate Development Organization (GREDA) in Ghana in a survey. The project team leaders were to first indicate the frequency of the communication ineffectiveness experienced among the team inherent from the unique HDP features of MHPs on a five point Likert scale ranging from not very frequent to very frequent. They were also to indicate the extent to which the communication ineffectiveness experienced was related to the unique HDP features. A total of 208 valid responses were received from various project team leaders on mass housing construction sites out of a purposive sample of 192 active members belonging to GREDA. The 208 responses were possible because majority of the sampled 192 GREDA members had multiple mass housing construction sites. By analysing the empirical data, SEM was adopted due to its superior advantage of exploring causal relationships among multiple independent and dependent variables over other multivariate analytical tools such as Analysis of Variance (ANOVA), Linear General Modelling (LGM) and Multiple Regression (MR) (Kline, 2011; Bentler and WU, 2005). This is because, the ANOVA, LGM and MR are unable to conduct causal relationships analysis between independent variables and multiple dependent variables (Kline, 2011). Hence by using the SEM approach, the contribution of the unique HDP features of mass housing to information flow and information composition communication ineffectiveness was explored. The conceptual variables in the hypothesised priori model (see Figure 1) were thereafter tested using SEM on the survey results aided by EQS 6.2 version software. 


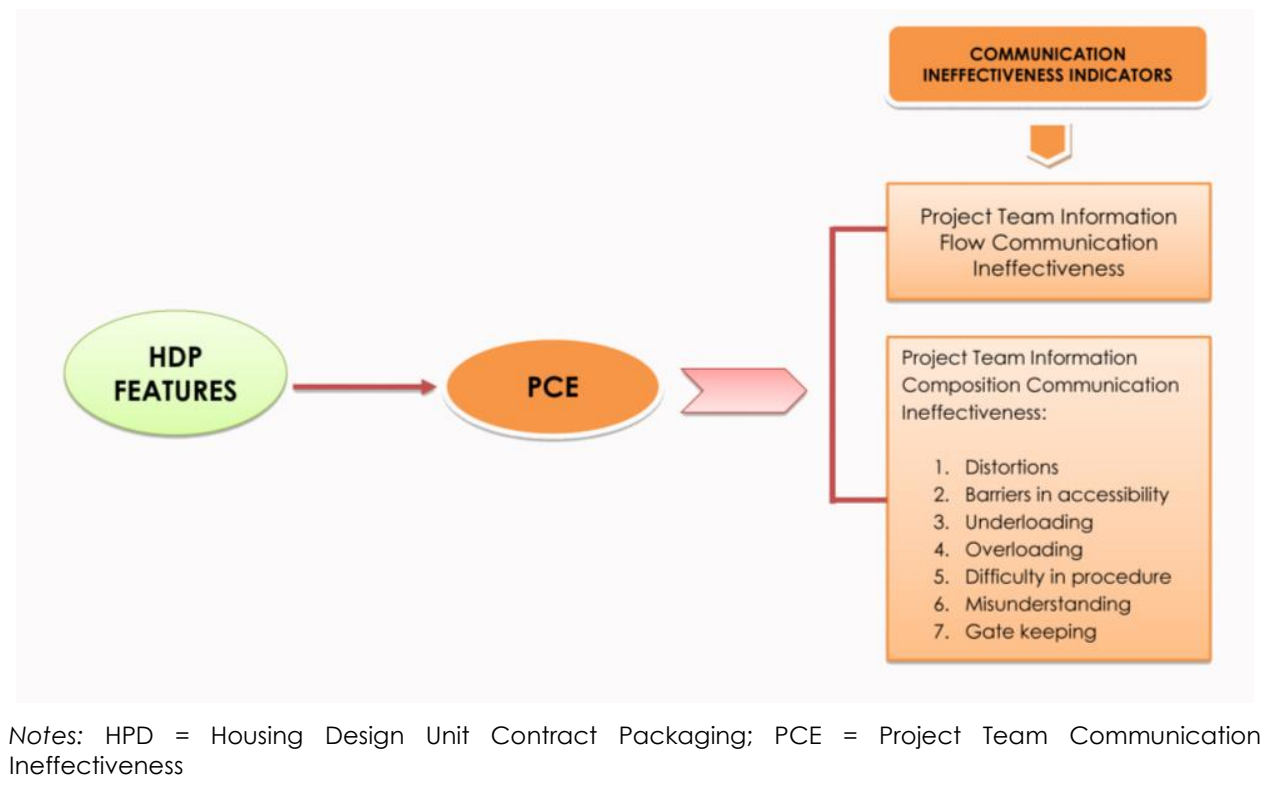

Figure 1. Conceptual Model of the HDP Induced Information Flow and Information Composition Communication Ineffectiveness

The data characteristics and the data analytic approach are presented in the following section.

\section{STRUCTURAL EQUATION MODEL, ESTIMATION AND RESULTS}

SEM is an analytical approach that demonstrate superior results in multiple causal relationships among set of variables which are denoted as exogenous (independent) and endogenous (dependent) variables (Kline, 2011; Bentler and Wu, 2005). The hypothesised structural model construct depict an investigation into the influence of the HDP factor (defined by six variables) on two project team communication ineffectiveness factors in the form of information flow (defined by seven variables) and information composition (defined by nine variables) (see Appendix).

These characteristics allowed for the adoption of the Confirmatory Factor Analysis (CFA) approach in the analytical process. The CFA refers to examination of the factor structure, score reliability and identifiability of a structural model involving factors prior to the testing of the main model (Kline, 2011; Bentler and Wu, 2005). In conducting the structural equation modelling analysis, the study adopted the two step approach recommended in literature (Byrne, 2006; Kline, 2005). The first step involved data characteristics and preliminary confirmatory factor assessments to determine the factor score reliability and identification of the three constructs in the hypothesised model defining the unique HDP features (exogenous variable), information flow communication ineffectiveness (endogenous variables) and information composition communication 
ineffectiveness (endogenous variables) to establish the fit and identifiability of the model as well as the most suitable estimation method (Byrne, 2006; Kline, 2005; Bentler and Wu, 2005).

The second step entailed the test of the full identified structural model by a CFA measurement approach. The choice of the CFA was underpinned by the already established factors defining the various constructs in the model and also its ability to control measurement invariances in SEM analysis (see Appendix). SEM CFA approach requires the examination of the data characteristics, score reliability, fit test and test of significance (Kline, 2011; Bentler and Wu, 2005). The data characteristics conducted showed that the empirical data collected was slightly non-normal with a Mardia coefficient of -7.1101 hence the Robust Maximum Likelihood (RML) estimation approach was adopted due to its ability to adjust for the effect of non-normality in the data to yield trustworthy unbiased results compared to the transformation approach (Kline, 2005; Bentler and Wu, 2005; Hu and Bentler, 1999).

A critical inspection of the data sets revealed that no data sets had missing values and no high level outliers. This allowed for the CFA analysis to proceed. From the preliminary CFA conducted, the results of the communalities revealed that, HDP4, HDP6, PCE1, PCE4, PCE9, PCE10, PCE11, PCE12 and PCE15 indicator variables emerged with an unacceptable levels of communalities $1<0.50$ ) (see Appendix) and were subsequently dropped. This meant that these variables do not sufficiently load their various constructs and thus have weak score reliability on their factors (Field, 2005) regardless of their importance and theoretical context of the study. This is because an acceptable score reliability must have a communality scores more than 0.50 (Field, 2005; Hair et al., 2013; Kline, 2005). This was conducted to ensure and demonstrate the extent to which the factor constructs in the model hypothetically relate to one another (Kline, 2011; lacobucci, 2010; Hair et al., 2013). Hence the summary of the variables were: Communication Ineffectiveness (information flow) PCE (four indicator variables); Communication Ineffectiveness (information Composition) PCE (five indicator variables); HDP (4 indicator variables) (see Table 1). Z-scores, test of significance, path coefficient, coefficient of determination (R2), Rho coefficient and Cronbach's alpha were subsequently assessed on the full structural hypothesised model to determine the reliability, validity, goodness of fit and significance of the variables in the model (Hair et al., 2013; Byrne, 2006).

The Robust Maximum Likelihood (RML) estimation method was conducted on the fully identified model to fit the data to the model. Consequently, in line with conventional requirements in SEM, by using the Robust Maximum Likelihood (RML) method, the robust statistics were reported in ascertaining the fit of the model. The model estimation process used the total 208 responses for the analysis of the full latent variables for information flow and information composition (Figure 2). According to Wong (2011), properly specified and estimated model will always converge. The model assessing the contribution of the HDP features to information flow and information composition converged at the 15th iterations suggesting that the model under study is properly specified. Additionally, the Bentler week's structural representation of the model revealed 15 dependent variables, 16 independent variables, 28 free parameters and 18 fixed non zero parameters. A well and properly specified structural equation model often has some fixed parameters and free parameters to be estimated from the data (Bentler and Wu, 
2005; Kline, 2005), hence the evaluative model (Figure 2) could be said to be well and adequately specified from the Bentler week's test results.

Table 1. Factor Loadings, Z-statistics, Variance Accounted for and Reliability and Construct Validity of Model Testing (Information Flow and Information Composition)

\begin{tabular}{|c|c|c|c|c|c|c|c|c|}
\hline $\begin{array}{l}\text { Indicator } \\
\text { Variable }\end{array}$ & $\begin{array}{c}\text { Unstandardised } \\
\text { Coefficient }(\lambda)\end{array}$ & $\begin{array}{c}\text { Standardised } \\
\text { Coefficient } \\
(\lambda)\end{array}$ & (Z-values) & $\begin{array}{l}\text { R Squared } \\
\left(R^{2}\right)\end{array}$ & $\begin{array}{c}\text { Path } \\
\text { Coefficient }\end{array}$ & $\begin{array}{l}\text { Cronbach's } \\
\text { Alpha }\end{array}$ & $\begin{array}{c}\text { Rho } \\
\text { Coefficient }\end{array}$ & $\begin{array}{c}\text { Significant } \\
\text { at } 5 \% \\
\text { Level? }\end{array}$ \\
\hline HDPI & $* * * * *$ & 0.801 & $* * * * *$ & 0.642 & 0.156 & .733 & .821 & Yes \\
\hline HDP2 & & 0.608 & 9.806 & 0.460 & $(0.486)$ & & & Yes \\
\hline HDP3 & & 0.683 & 12.055 & 0.594 & & & & Yes \\
\hline HDP5 & & 0.917 & 14.169 & 0.841 & & & & Yes \\
\hline PCE3 & $* * * * *$ & 0.691 & $* * * * *$ & 0.478 & 0.571 & & & Yes \\
\hline PCE7 & & 0.806 & 20.302 & 0.650 & & & & Yes \\
\hline PCE13 & & 0.783 & 18.489 & 0.613 & & & & Yes \\
\hline PCE14 & & 0.806 & 20.302 & 0.650 & & & & Yes \\
\hline PCE2 & $* * * * *$ & 0.720 & $* * * * *$ & 0.561 & 0.704 & & & Yes \\
\hline PCE5 & & 0.904 & 16.390 & 0.821 & & & & Yes \\
\hline PCE6 & & 0.871 & 11.443 & 0.786 & & & & Yes \\
\hline PCE8 & & 0.866 & 10.301 & 0.701 & & & & Yes \\
\hline PCE16 & & 0.945 & 24.611 & 0.856 & & & & Yes \\
\hline
\end{tabular}

Covariance Matrix revealed unstandardised average off-diagonal residual of 0.0323 whereas the standardised average off-diagonal residual was found to be 0.0668 . Byrne (2006) recounted that an acceptable well-fitting model should have its distribution of standardised residuals to be symmetrical and centered around zero. Hence the result of standardised average off-diagonal residual being 0.0668 could be described as very close to 0.0 and thus very suggestive of an acceptable and adequate fit to the sample data. Following this, further tests of goodness-of-fit were conducted as suggested by Kline (2005), Byrne (2006) and Hair et al. (2013) to make a dichotomous decision to accept or reject the model or modify it. From the summary of the goodness of fit analysis presented in Table 2, the $S$ - BX2 yielded 171.2968 with 63 degrees of freedom (df) and associated probability of $p=0.000$. Consequently, the normed chi-square value $(S-B \times 2 / d f)$ was 2.67. Kline (2005) suggested that a normed value up to 3.0 is considered good fit whereas a value up to 5.0 is an acceptable fit.

Ideally, for a model that fits the data, the $x 2$ or $S-3 \times 2$ would not be significant $(p>0.05)$ (Kline, 2005). Hence, it could be said that the postulated model fit the sample data adequately. Similarly, from the results on the Robust Fit Indexes for full structural model reported in Table 2, the CFI was found to be 0.936 . This was found to be close to the conventional cut-off of 0.90 (acceptable) and 0.95 (good fit) and thus could be described as having an acceptable fit (Kline, 2005). Additionally, the RMSEA yielded 0.028, an indication of having a good fit because it meets the conventional cut-off values of 0.080 (acceptable) and 0.05 (good fit) (Kline, 2005). However, the upper boundary of the RMSEA with $90 \%$ confidence interval was slightly above the recommended cut-off value of 0.95 . Inspite of this, the model could be said to have an indication of good conditions for the model acceptance (see Table 2). 


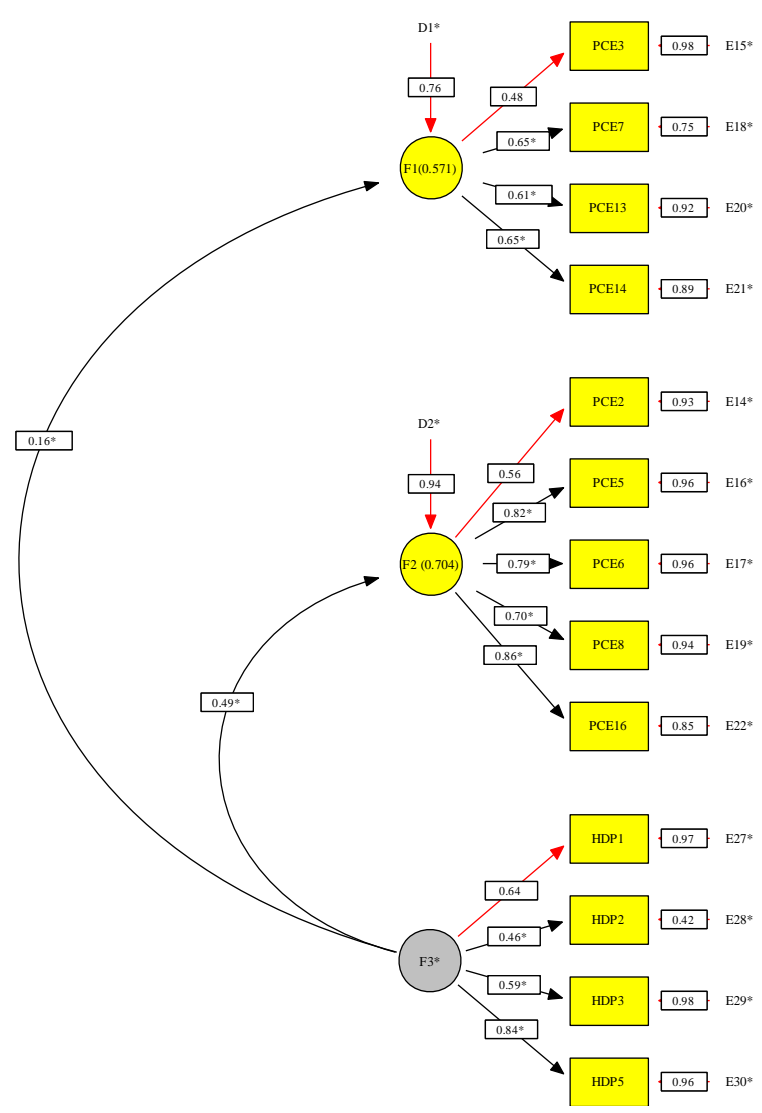

Notes: Model results EQS 6 final200 phd.eds chi sq. $=168.34, P=0.00$, Comparative Fit Index $(\mathrm{CFI})=0.94$, Root Mean Square Error Approximation (RMSEA) $=0.03$

Figure 2. Results of the HDP induced Information Flow and Information Composition Communication Ineffectiveness

The reliability and validity assessment also revealed the Cronbach's alpha and the Rho coefficient as 0.733 and 0.821 respectively. The value of the Cronbach's alpha is above the recommended point of 0.700 (Hair et al., 2010; 2013). Additionally the Rho coefficient value of 0.821 is considered very good and thus could be deduced that the model is acceptable indicating a good internalconsistency reliability and validity (Kline, 2005; Hair et al., 2013). This unequivocally suggests that the indicator variables correctly and adequately define and measure the constructs. Also, all the factor loadings recorded in Table 1 were above 0.700 and all the $R^{2}$ values were above 0.50 except for variables HDP2 and PCE3. This suggests adequate support for convergent validity and good average variance extracted (Kline, 2005; Hair et al., 2013). Lastly, the test of significance results revealed that all the Z-statistic values were greater than 1.96 with their corresponding significant test values being less than $0.05(p<0.05)$ indicating statistically significance and acceptable results. It could be remarked from the results from the CFA analysis that the robust fit indexes and the residual covariance 
analysis met the recommended cut-off criteria and thus can be reported that the model adequately fit the data. Hence, from above, the results suggest that the overall hypothesised structural model evaluating both the information flow and information composition had a good-fit to the sample data and that the results are feasible.

Table 2. Robust Fit Indexes for Structural Model Testing Contribution of Mass Housing Features to Information Flow and Information Composition

\begin{tabular}{|c|c|c|c|}
\hline Fit Index & Cut-Off Value & Estimate & Remarks \\
\hline$x^{2}$ & & $\begin{array}{l}168.344 \text { on } 63 \text { degrees of } \\
\text { freedom }\end{array}$ & \\
\hline$S-B x^{2}$ & & $\begin{array}{l}171.2968 \text { on } 63 \text { degrees of } \\
\text { freedom }\end{array}$ & \\
\hline$d f$ & $x>0.00$ & $63($ Normed $=2.67)$ & Good fit \\
\hline CFI & $\begin{array}{l}x \geq 0.90 \\
\text { (acceptable) } \\
x \geq 0.95 \text { (good fit) }\end{array}$ & 0.936 & Acceptable fit \\
\hline RMSEA & $\begin{array}{l}x \leq 0.08 \\
\text { (acceptable) } \\
x \leq 0.05 \text { (good fit) }\end{array}$ & 0.028 & Good fit \\
\hline $\begin{array}{l}\text { RMSEA } \\
90 \% \mathrm{Cl}\end{array}$ & & $(0.020, .065)$ & Good fit \\
\hline$p$ value & $x \geq 0.05$ & 0.000 & \\
\hline
\end{tabular}

Results of the Contribution of HDP Features to Communication Ineffectiveness Level

A critical inspection of the solution obtained (see Figure 2 and Table 1) by examining the statistical significance of the parameter estimates, the test statistics, the standardised parameter estimates and the test-statistics (Z-test) obtained in the solution revealed that the parameter estimates were reasonable in terms of their magnitude, signs and statistical significance and thus adequately measures more than $25 \%$ (above moderate effect on their respective construct measures). This is because their Z-test statistics were greater than the conventional minimum of 1.96 and their respective factor loadings and predictive determinants $\left(R^{2}\right)$ were significant (Kline, 2005; Byrne, 2006; Bentler and Wu, 2005).

From the path coefficient generated, it could be seen that HDP yielded an effect of 0.16 and 0.49 to the information flow and information composition communication ineffectiveness among the project team. The path coefficient are the composite effect of a factor $\left(R^{2}\right)$ on the endogenous variable which is interpreted as the model's predictive accuracy and thus represents the exogenous variable's combined effect on the endogenous variable(s) (Hair et al., 2013). According to Hair et al. (2013), this effect range from 0.00 to 1.00 with 1.00 suggesting an absolute predictive accuracy. It is further indicated that an $R^{2}$ values of $0.75,0.50,0.25$, respectively, describes substantial, moderate and weak level of predictive accuracy (Hair, Ringle and Sarstedt, 2011; Wong, 2011). Additionally, an $R^{2}$ value less than 0.100 is deemed an insignificant effect on the 
endogenous variable (lacobucci, 2010; Hair, Ringle and Sarstedt, 2011 ; Hair et al., 2013).

From Figure 2, the factor loadings and effects indicate that the HDP features contribute a weak effect to information flow and moderate effect to information composition communication ineffectiveness respectively. Additionally, the results reveal that in information flow communication ineffectiveness, the influence of the HDP features results in PCE3: Receiving less information than expected from team participants for tasks, PCE7: Late delivery of needed communicated information, PCE13: Difficulty in disseminating information among project team and PCEI4: Difficulty in accessing communicated information from channels. With regards to information composition related communication ineffectiveness, the influence of the HDP features results in PCE2: Lack of consistency in communicated information leading to lack of coordination among project team, PCE5: Receiving conflicting information from team participants, PCE6: Lack of clarity in communicated information resulting in different interpretations, PCE8: Misunderstanding of communicated information and PCEl6: Lack of defined roles and responsibilities among members of the team leading to communication failure.

Likewise, a critical assessment of the influence of the HDP features suggest that, of all the variables contained, the features HDPl: Composition of housing design in each contract packages under housing scheme and HDP5: Packaging of "preliminaries items" adopted under standardised repetitive housing units under scheme are deemed to be contributing substantially to the overall composite effect to the communication ineffectiveness. The variables HDP2 and HDP3 are said to be contributing moderately to the composite effect of the HDP factor to the overall communication ineffectiveness levels. It could be suggested from the results that the HDP features of MHPs influence the information composition communication ineffectiveness substantially than with information flow.

\section{DISCUSSIONS OF FINDINGS}

Factors due to project organisation such as design and contract packaging are considered as critical factors that induce team break down and communication ineffectiveness among project teams and stakeholders and consequently results in project failures (Khanzadi, Dabirian and Youneszadeh, 2008). In repetitive design projects, it is said that good contract packaging is very useful in ensuring good design management and managerial efficiencies (Gray and Hughes, 2012). In this study, the results revealed that certain attributes of HDP features such as "composition of housing design in each contract packages under housing scheme" and "packaging of 'preliminaries items' adopted under standardised repetitive housing units under scheme" induce substantial effects to the overall contribution of the factor to the information inflow and information composition communication ineffectiveness among the project team. Indeed, the results indicate that the overall factor contribute from weak to moderate effect to the information flow and composition ineffectiveness respectively. Even though this contribution can be considered not to be substantial, it should not to be taken lightly among stakeholders.

It is well acknowledged that a well packaged contract on any project type enhances information accuracy, information coordination and mutual 
understanding of the shared project related information (Liu, 2009; Xie, Thorpe and Baldwin, 2000). The Entrusty Group (2009) revealed that detailed and unambiguous preliminaries are critical information that enhances understanding, accuracy and formal obligation of participants. However, in the practical perspective of mass HDP, various housing units which may be repetitive could be included in one packaging. This often induces challenges in communicating exact scope and content of preliminaries to capture all the various units contained in the package. Chou and Yang (2012) indicated that contract packaging on construction projects generally influences communication methods, communication requirements and reporting systems among the project participants and thus should be well defined before the start of the project in order to increase communication success.

The practical antecedent of this finding is that, in developed countries, contract packaging are often designed to suit the project environment and associated characteristics. In Ghana, the situation appears to be different: a standard contractual arrangement and packaging appears to be adopted for all projects without particular practical reference to the needs and challenges on the project. For example in developed countries, different contract packaging and arrangements may be adopted on a single project to define the various roles, subcontracting and task activities to enhance management structure, organisation and communication. The absence of this on MHPs coupled with the challenging project environment is likely to account for this related communication ineffectiveness.

Likewise, empirical evidence of the extent of the influence established here on MHPs, the results also generally are in line with findings reported in previous research on traditional "one-off" projects (Liu, 2009; Xie, 2002; Chou and Yang, 2012). However, it is interesting to note that, on mass housing, construction and engineering elements adopted are crucial in co-ordination and management of the construction process (Zairul and Rahinah, 2011), here in this study the variable "construction elements and components adopted in design units in contract packages under scheme" is perceived to not significantly contribute to communication ineffectiveness. A plausible explanation to this development is that, though the influence of this variable is not directly seen, it could be inducing an indirect effect that may not be at the attention of the project team. Against this, it could be suggested that project teams could still consider this variable as very significant as communication is central to the integration of the construction elements and technology especially among task team leaders and artisans. Additionally, the poor show of this variable against report on it in vast literature could be explained that, practically, the approach to housing development is yet to be fully integrated into the industry as most mass housing development organisation still lean towards the in-situ conventional method as against the use of concurrent modular engineering elements.

\section{CONCLUSIONS}

Before this study, several researches hypothetically acknowledged the perceived incidence of communication ineffectiveness inherent from the unique characteristics and features of MHPs. Against the background of limited studies 
providing an empirical evidence of the inherent communication ineffectiveness induced by the unique features of mass housing, this study has been undertaken in an effort to close this knowledge gap in mass housing delivery. By focusing on the unique HDP features of mass housing, the results from the SEM analysis yielded empirical support to the perceived induced communication ineffectiveness inherent from the unique attributes of MHPs compared to traditional "one-off" construction building projects (Enshassi, 1997; Ahadzie, Proverbs and SarkodiePoku, 2014; Zairul and Rahinah, 2011). Hence, it could thus be concluded that, the unique HDP features of mass housing contribute to the overall communication ineffectiveness among mass housing project teams. In respect of information flow the feature makes a weak effect whereas with information composition related communication ineffectiveness, there is a moderate effect.

The evaluative assessment given by this study suggests that the HDP feature induces communication inaccuracies, information misunderstanding, communication barriers and information overload among the mass housing project teams. From this, it is quite clearly evident from the findings that the contribution of the unique HDP features of mass housing cannot be overlooked or ignored. Against this, it is very critical for mass housing stakeholders and practitioners to consider these findings in their communication planning, management in order to adopt communication medium and strategies necessary to engender the needed effectiveness towards delivery success.

\section{LIMITATIONS OF STUDY AND FUTURE WORK}

It is well acknowledged that, knowledge of the influence of the unique HDP features on MHPS team communication performance has a significant role in communication medium selection and communication planning and strategies adopted in MHP delivery. Hence, the insights given by this study could be useful to MHP communication planning and management to engender managerial effectiveness and delivery successes. However, it is extremely significant to highlight the limitations of the study. The factors that influence communication performance outcome could be said to be diverse and multivariate having a complex and multi-faceted phenomenon. The model by Kwofie et al. (2014) indeed identified project related factors and behavioural competencies as the critical attributions of MHP communication outcome. Here in this study, the focus has been on the HDP which is inclined to the project related factors. It is important to note that, this study does not consider the tacit knowledge component of communication performance outcome.

Also, another key limitation worth mentioning is that the empirical data was collected in Ghana suggesting that, the result and finding could only be generalised to the Ghanaian context. However, it is important for readers to note that, this should not nullify the application of the findings in other developing countries with similar cultural and practical characteristics of construction project management practices and construction project delivery. However, attempt to assess the influence of both project related factors and behavioural competencies by quantifying the effects of all possible inter-causal relationships will be a herculean task and bulky to present in one paper here. Hence, given that behavioural competencies which is inclined to the tacit knowledge of the 
communication task performers has a significant contribution to the communication outcome, further studies are needed to bridge this knowledge gap as a limitation of the study. Such knowledge could complement the assessments and extend the findings and knowledge given in this study. Additionally, Kwofie et al. (2014) and Ahadzie, Proverbs and Sarkodie-Poku (2014) established that MHPs exhibit unique, multiple site features and procurement structures compared to traditional "one-off" projects which significantly induce communication and documentation challenges. Hence, it is extremely important for further studies to be conducted to extend the knowledge of the perceived communication ineffectiveness inherent from the unique attributes of MHPs.

\section{APPENDIX}

\section{Communalities}

\begin{tabular}{|c|c|c|c|}
\hline \multirow{2}{*}{$\begin{array}{l}\text { S/No } \\
\mathrm{HDPl}\end{array}$} & \multirow{2}{*}{$\begin{array}{l}\text { Description of variables in the multiple construction sites } \\
\text { and management style (MCS) factor } \\
\text { Composition of housing design in each contract packages } \\
\text { under housing scheme }\end{array}$} & \multicolumn{2}{|c|}{ Initial Extraction } \\
\hline & & 1.000 & .779 \\
\hline HDP2 & $\begin{array}{l}\text { Construction elements and components adopted in } \\
\text { design units in contract packages under scheme }\end{array}$ & 1.000 & .644 \\
\hline HDP3 & $\begin{array}{l}\text { Packaging of "one-off" infrastructure: e.g. water, electricity, } \\
\text { road, etc. on housing units under scheme }\end{array}$ & 1. & .663 \\
\hline HDP4 & $\begin{array}{l}\text { Contractual arrangement on "one-off" infrastructure: e.g. } \\
\text { water, electricity, road etc. on housing units under scheme }\end{array}$ & 1.000 & $.425^{*}$ \\
\hline HDP5 & $\begin{array}{l}\text { Packaging of "preliminaries items" adopted under } \\
\text { standardised repetitive housing units under scheme }\end{array}$ & 1.000 & .737 \\
\hline \multirow[t]{2}{*}{ HDP6 } & Contract type adopted for preliminary items & 1.000 & $.465^{*}$ \\
\hline & \multicolumn{3}{|c|}{$\begin{array}{l}\text { Description of variables in the project team communication performance } \\
\text { (PCE) factor (information flow) }\end{array}$} \\
\hline PCE3 & $\begin{array}{l}\text { Receiving less information than expected from team } \\
\text { participants for tasks }\end{array}$ & 1.000 & .758 \\
\hline PCE7 & Late delivery of needed communicated information & 1.000 & .638 \\
\hline PCE10 & Receiving more information than necessary for the tasks & 1.000 & $.422 *$ \\
\hline PCE12 & $\begin{array}{l}\text { Withholding of part of the information by the one who } \\
\text { controls communication }\end{array}$ & 1.000 & $.275^{*}$ \\
\hline PCE13 & Difficulty in disseminating information among project team & 1.000 & .582 \\
\hline PCEl4 & $\begin{array}{l}\text { Difficulty in accessing communicated information from } \\
\text { channels }\end{array}$ & 1.000 & .717 \\
\hline PCE15 & $\begin{array}{l}\text { Withholding of whole of the information by the one who } \\
\text { controls communication }\end{array}$ & 1.000 & $.466^{*}$ \\
\hline
\end{tabular}




\begin{tabular}{|c|c|c|c|}
\hline \multirow[b]{2}{*}{ PCEl } & \multicolumn{3}{|c|}{$\begin{array}{l}\text { Description of variables in the project team communication performance } \\
\text { (PCE) factor (information composition) }\end{array}$} \\
\hline & Persistent change in content of communicated information & 1.000 & $.451^{*}$ \\
\hline PCE2 & $\begin{array}{l}\text { Lack of consistency in communicated information leading } \\
\text { to lack of coordination among project team }\end{array}$ & 1.000 & .651 \\
\hline PCE4 & $\begin{array}{l}\text { Persistent change in meaning of communicated } \\
\text { information }\end{array}$ & 1.000 & $.402^{*}$ \\
\hline PCE5 & Receiving conflicting information from team participants & 1.000 & .678 \\
\hline PCE6 & $\begin{array}{l}\text { Lack of clarity in communicated information resulting in } \\
\text { different interpretations }\end{array}$ & 1.000 & .585 \\
\hline PCE8 & Misunderstanding of communicated information & 1.000 & .681 \\
\hline PCE9 & $\begin{array}{l}\text { Lack of conciseness in communicated information among } \\
\text { the project team }\end{array}$ & 1.000 & $.281^{*}$ \\
\hline$\overline{\text { PCE1 } 1}$ & $\begin{array}{l}\text { Lack of coherency in communicated information resulting } \\
\text { in different interpretations }\end{array}$ & 1.000 & $.430^{*}$ \\
\hline PCE16 & $\begin{array}{l}5 \text { Lack of defined roles and responsibilities among members } \\
\text { of the team leading to communication failure }\end{array}$ & 1.000 & .733 \\
\hline
\end{tabular}

Notes: Extraction Method: Principal Component Analysis

\section{REFERENCES}

Adinyira, E., Ahadzie, D.K. and Kwofie T.E. (2013). Determining the Unique Features of Mass Housing Projects (MHPs). In S. Laryea and S.A. Agyepong (eds.). Proceedings of the 4th West Africa Built Environment Research (WABER) Conference. Accra, Ghana, 12-14 August. Accra, Ghana: WABER, 381-390.

Ahadzie, D., Proverbs, D. and Olomolaiye, P. (2007). Critical success criteria for mass housing building projects in developing countries. International Journal of Project Management, 26(6): 675-687. doi: 10.1016/j.jproman.2007.09.006.

Ahadzie, D., Proverbs, D. and Sarkodie-Poku, I. (2014). Competencies required of project managers at the design phase of mass housing building projects. International Journal of Project Management, 32(6): 958-969. doi: 10.1016/j.jproman.2013.10.015.

Bentler, P. and WU, E. (2005). EQS 6.1 for Windows. Encino, CA: Multivariate Software. Available at: http://down.cenet.org.cn/upfile/83/200931814911118.pdf [Accessed on 11 February 2015].

Byrne, B.M. (2006). Structural Equation Modeling with EQS: Basic Concepts, Applications and Programming. Mahwah, NJ: Lawrence Erlbaum Associates.

Chou, J.S. and Yang, J.G. (2012). Project management knowledge and effects on construction project outcomes: An empirical study. Project Management Journal, 43(5): 47-67. doi: 10.1002/pmj.21293.

Construction Industry Institute (CII). (1997). An assessment tool for improving project team communications. University of Texas at Austin Research Report. Austin, TX: Cll, 105-11. 
El-Rayes, K., Ramnathan, R. and Moselhi, O. (2000). An object oriented model for planning and control of housing construction. Construction Management and Economics, 20(3): 201-210. doi: 10.1080/01446190110115312.

El-Saboni, M., Aouad, G. and Sabouni, A. (2009). Electronic communication systems effects on the success of construction projects in United Arab Emirates. Advanced Engineering Informatics, 23(1): 130-138. doi: 10.1016/j.aei.2008.07.005.

Enshassi, A. (1997). Site organization and supervision in housing projects in the Gaza strip. International Journal of Project Management, 15(2): 93-99. doi: 10.1016/S0263-7863(96)00044-0.

Enshassi, A. and Burgess, R. (1991). Managerial effectiveness and the style of management in the Middle East: An empirical analysis. Construction Management and Economics, 9(1): 79-92. doi: 10.1080/01446199100000008.

Entrusty Group. (2009). What are preliminaries and how to evaluate them? Master Builders Journal, 1: 80-90.

Field, A. (2005). Discovering Statistics Using SPSS for Windows. London: London Sage Publications.

Gray, C. and Hughes, W. (2012). Building Design Management. Oxford: Butterworth-Heinemann.

Hair, J.F., Black, W.C., Babin, B.J., Anderson, R.E. and Tatham, R.L. (2010). Multivariate Data Analysis with Readings. 7th Ed. Upper Saddle River, NJ: Pearson/Prentice Hall.

Hair, J.F., Hult, G.T.M., Ringle, C.M. and Sarstedt, M. (2013). A Primer on Partial Least Squares Structural Equation Modeling (PLS-SEM). Thousand Oaks, CA: Sage Publications.

Hair, J.F., Ringle, C.M. and Sarstedt, M. (2011). PLS-SEM: Indeed a silver bullet. Journal of Marketing Theory and Practice, 19(2): 139-151. doi: 10.2753/MTP1069-6679190202.

Hu, L. and Bentler, P.M. (1999). Cutoff criteria for fit indexes in covariance structure analysis: Conventional criteria versus new alternatives. Structural Equation Modeling, 6(1): 1-55. doi: 10.1080/10705519909540118.

lacobucci, D. (2010). Structural equations modeling: Fit indices, sample size and advanced topics. Journal of Consumer Psychology, 20(1): 90-98. doi: 10.1016/j.jcps.2009.09.003.

Khanzadi, M., Dabirian, S. and Youneszadeh, Y. (2008). Assessment of Effective Factors on Time, Cost and Quality of Mass House Building Projects Using Analytic Hierarchy Process: A Case Study in Tehran. Pittsburgh, Pennsylvania: International Symposium on the Analytic Hierarchy Process (ISAHP). Available at: http://www.isahp.org/2009Proceedings/Final_Papers/ 18_Dabirian_EFFECTIVE_FACTORS_OF_HOUSING_MASS_PRODUCTION_PROJE CTS_REV_FIN.pdf [Accessed on 12 July 2013].

Kline, R.B. (2011). Principles and Practice of Structural Equation Modeling. 3rd Ed. New York: Guilford Press. (2005). Principles and Practice of Structural Equation Modeling. 2nd Ed. New York: Guilford Press. 
Kwofie, T.E., Fugar, F.D.K., Adinyira, E. and Ahadzie, D.K. (2014). A conceptual framework for evaluating communication performance among mass housing project team. In O. Ejohwomu and O. Oshodi (eds.). Proceedings: 3rd International Conference on Infrastructure Development in Africa. Abeokuta, Nigeria, 17-19 March. Abeokuta, Nigeria: Kwame Nkrumah University of Science and Technology, 6-21.

Liv, Y. (2009). Critical factors for managing project team communication at the construction stage. PhD diss. The Hong Kong Polytechnic University.

Murray, M., Tookey, J.E., Langford, D.A. and Hardcastle, C. (2000). Project communication variables: A comparative study of US and UK construction industry perceptions. In Proceedings of ARCOM Conference. Glasgow, UK: Association of Researchers in Construction Management, 813-822.

Project Management Institute (PMI). (2008). A Guide to the Project Management Body of Knowledge. 3rd Ed. Pennsylvania: PMI.

Skulmoski, G. and Hartman, F. (2010). Information systems project manager soft competencies: A project-phase investigation. Project Management Journal, $41(1): 61-80$.

Thomas, S.R., Tucker, R.L. and Kelly, W.R. (1998). Critical communication variables. Journal of Construction Engineering and Management, 124(1): 58-66. doi: 10.1061/(ASCE)0733-9364(1998)124:1 (58).

Wong, K.K. (2011). Book review: Handbook of partial least squares: Concepts, methods and applications. International Journal of Business Science and Applied Management, 6(2): 52-54.

Xie, C., Wu, D., Luo J. and Hu, X. (2010). A case study of multi-team communications in construction design. Supply Chain Management, 15(5): 363-370. doi: 10.1108/13598541011068279.

Xie, X. (2002). Communications in construction design. PhD diss. Loughborough University.

Xie, X., Thorpe, A. and Baldwin, A.N. (2000). A survey of communication issues in construction design. In A. Akintoye (ed.). 16th Annual ARCOM Conference Vol. 2. Glasgow Caledonian University, 6-8 September. Glasgow, UK: Association of Researchers in Construction Management, 771-780.

Zairul, M.M.N. and Rahinah, I. (2011). Identifying concurrent engineering (CE) elements for mass housing industry. Journal of Advanced Manufacturing Technology, 5(1): 61-78. 